\title{
THE COMBINATION OF SELECTED MANAGEMENT INSTRUMENTS TO ANALYZE QUALITY PROBLEMS
}

\begin{abstract}
The aim of the article is to propose the combination of selected quality management instruments in a sequential and repetitive manner and to identify the incompatibilities and causes of its occurrence. This is a combination of techniques i.e.: brainstorming (BM), causes and effects diagram, multiply voting, and the 5Why method. The test of the proposed combination of the selected quality management instruments was made for the problem of the incompatibility of the product in an enterprise located in the Podkarpacie. This problem was the non-metallic inclusions on the bearing housing from CPW 407 steel. The proposed combination of the selected quality management instruments was integrated with the non-destructive testing (NDT). The originality of the study is to propose the combination of selected quality management instruments as a part of a single method, whose stages can occur in a sequential and repetitive manner.
\end{abstract}

Keywords: quality, quality management, production engineering, Ishikawa diagram, 5Why.

\section{INTRODUCTION}

The need of manufacturing products oriented on a customer $(\mathrm{Li}$, Pomegbe, Dogbe, 2018), and also the following changes and turbulent environment, has generated the necessity to support actions of organizations on different stages (Cegliński, 2015; Siwiec, Bednarova, Pacana, 2020). It is important that these actions support the quality ones, which are applied in the improved performance of the production and service enterprises (Nilsson, Johnson, Gustafsson, 2001). Searching for different solutions in products to meet both the current and future needs of customers is one of these actions (Blocker, Flint, Myers, Slater, 2011). Also, these actions are applied to include the possibilities of problems occurence with the quality of products, and, the need to effectively solve these problems, and simultaneously to prevent the occurrence in the future (Slater, Narver, 1994). Hence, it is appropriate to use, for example, effective quality management instruments (Harmol, 2008).

The most popular quality management instruments are e.g. the Ishikawa diagram (causes and effects diagram), which is applicable to identify the source causes of the problem. This diagram is the model in which the correlations between the effect and many

\footnotetext{
${ }^{1}$ Dominika Siwiec, MSc, Rzeszow University of Technology, Rzeszów, Aleja Powstańców Warszawy 12, 35-959 Rzeszów; e-mail: d.siwiec@prz.edu.pl (corresponding author). ORCID: 0000-0002-6663-6621.

2 Stanislav Vandžura, Eng. Technical University of Kosice, Park Komenského 19, 04001 Košice, Slovakia. ORCID: 0000-0003-1850-7611
} 
causes are present in a visual manner (Ilie, Ciocoiu, 2010). The Ishikawa diagram was applied e.g. for the analysis of the probability and the impact of the problem as part of the assessment of the risk for each category of causes (Ilie, Ciocoiu, 2010). Another example of the use of the Ishikawa diagram is a visualization of the causes into an easier analysis and categorization (Coccia, 2017; Luo, Wu, Duan, 2018). Therefore, the authors of the work (Ishii, Lee, 1995) used the so-called inverted Ishikawa diagram to project assembly and to analyze the modes and effects of the process failure (FMEA). Brainstorming (BM) and multiple voting are other nother popular quality management instruments. For example, brainstorming has been applied to generate as many ideas as possible, taking into account the ideas which concerned the causes and improvement actions in the context of solving the problem, as in works (Putman, Paulus, 2008; Rossiter, Lilien, 1994). In turn, multiply voting has been applied as part of teamwork to make the choice in the context of solving the decision problems, as in article e.g. (Pacana, Siwiec, Bednarova, 2020). The next popular quality management instrument is the 5 Why method (Why-Why), which is used to search the causes which are in the source of the problem (Gołaś, Mazur, Mrugalska, 2016). For example, the author of the article (Wolniak, 2019) applied the 5Why method to analyze the downtime in the production process. Other examples incude the articles i.e. (Dziuba, Jarossova, Gołębiecka, 2014; Pacana, Siwiec, Bednarova, 2019), in which the 5Why method was used to search the cause in the source of incompatibility of the product. Due to the fact that those methods are popular and effective as part of the analysis of the problems, and also the incompatibility with the quality of the product (Nilsson, Johnson, Gustafsson, 2001), it was considered as justified to use these methods as a single combined method.

Hence, the aim of the article is to propose a combination of the selected quality management instruments to identify the incompatibilities and their causes, which occurs in a sequential and repetitive manner. Brainstorming (BM), causes and effects diagram, multiple voting, and the 5 Why method were the combination. The test of the proposed combination of selected quality management instruments was carried out for the problem of non-metallic inclusions on the bearing housing made of CPW 407 steel, which were detected at a Podkarpacie enterprise as a part of non-destructive testing (NDT).

\section{METHOD}

The method consisted of quality management instruments which were integrated with non-destructive testing (NDT). The instruments were: brainstorming (BM), causes and effects diagram, multiple voting, and the 5 Why method. The choice of these instruments was determined by their confirmed effectiveness for analyzing the problems with the quality of the product. The concept of the proposed method involved the generation of possible causes of the problem by a team of experts, successively grouping them and visualizing them in a causes and effects diagram. Next, the main cause is selected by multiple voting (the cause which is the most important from the view of the occurrence of the problem), and then by using the 5 Why method, the cause which is in the source of the problem is identified. Accordingly, the repetition of the proposed method was adopted as a part of identification of improvement actions, which have to eliminate or reduce the occurrence of the problem in the future. The proposed method consists of five main stages (Fig. 1). 


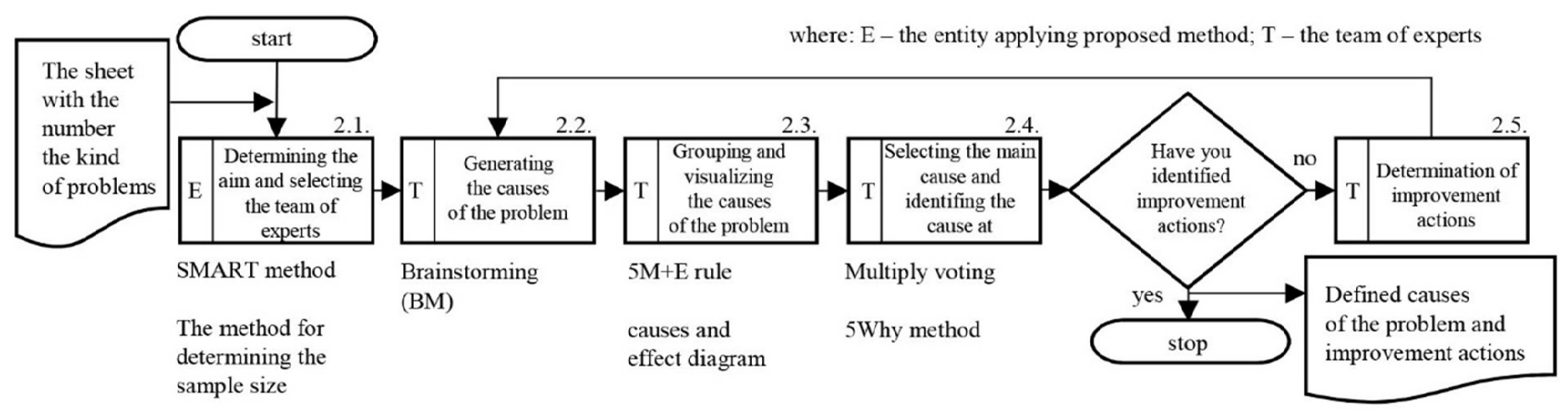


The algorithm of the proposed method was extended to include information of using the quality management instruments in a combined way.

\subsection{Determining the aim and selecting the team of experts}

The first stage of the proposed method is to determine the aim and select the team of experts. This stage is carried out by the entity applying the proposed method. The aim should refer to the solution of problem (i.e. in the analysed context to the identification of the causes of the problem and improvement actions). The problem can be arbitrary, depending on the needs of the entity applying the proposed method. For example, the problem is incompatibility, which has occurred most frequently. As a part of determining the aim, it is effective to use the SMART method (Lawlor, Hornyak, 2012). In turn, the team of experts is selected by the entity applying the method. This team is responsible for solving the problem by using the proposed method.

\subsection{Generating the causes of the problem}

The second stage of the proposed method is to generate the causes of the problem. It refers to generating as many causes of the problem as possible. To make it happen, it is proposed to use brainstorming (BM) among the selected team of experts. This stage should be carried out according to the methodology of the brainstorming method (BM), as is shown in the literature, e.g. (Putman, Paulus, 2008; Rossiter, Lilien, 1994).

\subsection{Grouping and visualizing the causes of the problem}

The third stage of the proposed method is to group and visualize the causes of the problem. This stage is carried out by the selected team of experts. For this purpose, all the generated (on stage 2.2.) causes of the problem should be analyzed in the context of categories (thematic groups) to which these categories belong. The categories (thematic groups) of the causes are selected by the team of experts in terms of the character of the problem. Also, these categories should be determined in the context of the causes of its occurrence. It is possible to use e.g. the Ishikawa rule, i.e. $5 \mathrm{M}+\mathrm{E}$ : man, method, machine, material, management, and environment (Gołaś et al., 2016; Ulewicz, 2014). Then, it is necessary to group the causes into these categories. Hence, it is possible to use the causes and effect diagram (so-called fishbone), which is shown e.g. in (Pacana, Siwiec, Bednarova, Hajduova, 2019).

\subsection{Selecting the main cause and identifying the cause at the source of the problem}

The fourth stage of the proposed method is to select the main cause of the problem and identify the cause in the source of the problem. This stage is carried out by the selected panel of experts. Therefore, initially, the main cause of the problem is selected by the team of experts by multiple voting. Hence, each team member votes for a single freely selected cause (among all generated causes). The team member votes for the cause which has the greatest impact on the occurrence of the problem. The main cause of the problem is the cause which has the highest number of votes.

Then, the team of experts determines the causes in the source of the problem. To do it, the 5 Why method (i.e. Why-Why) is used in the context of the determined problem and the selected main cause of the problem. The manner uses the 5Why method shown e.g. in (Ershadi, Kazemi, 2018). As a result, the cause or causes in the source of the problem are achieved. 


\subsection{Determination of improvement actions}

The fifth stage of the proposed method is to determine the improvement actions, i.e. actions thanks to which the problem will be reduced or eliminated. To do this, it is necessary to repeat the method (starting from stage 2.2.). Each stage of the method should be carried out in the context of identifying improvement actions. If it is appropriate, the selection of improvement actions can be made after the development the causes and effect diagram. Then, the team of experts, through multiple voting, indicates which improvement action or actions should be implemented first. After the determination of the improvement actions it is possible to end the proposed method.

\section{RESULTS AND DISCUSSION}

The test of the proposed, combined method (the combination of the selected quality management instruments) was carried out for the problem which was relatively often identified in one of the enterprises of the Podkarpacie. The problem was non-metallic inclusions on the CPW 407 steel bearing housing. This product has been used in the aviation and automotive industry. The non-metallic inclusions are in the form of particles of various shapes and sizes. In the case of steel or alloys, these inclusions generate many material defects and can significantly affect functional properties (Lis, 1995). Therefore, it was important to stabilize this product in terms of quality. In the enterprise, this problem was identified by non-destructive testing (NDT), i.e. magnetic-powder method (Fig. 2).

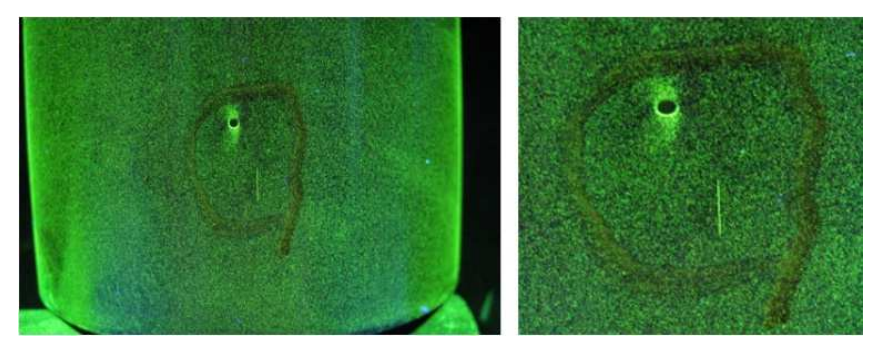

Fig. 2. The example of the non-metallic inclusions identified on bearing housing

The application of the magnetic-powder method was conditioned by the type of material the product was made, and the requirements of the customer who has ordered the inspection. Therefore, the proposed combination of selected quality management instruments was integrated with NDT research with the aim of complex analysis of the non-metallic inclusions on the bearing housing.

According to the proposed method, initially, the aim was determined. Hence, the aim was to determine the causes of the non-metallic inclusions on the CPW 407 steel bearing housing. Also, the aim was to identify improvement actions to reduce or eliminate this problem. Then, among the selected team of experts, brainstorming (BM) was done as a part of identifying the causes of non-metallic inclusions on the analysed product. Then, by using the $5 \mathrm{M}+\mathrm{E}$ rule, all causes were grouped and visualized on the causes and effects diagram. The results from these activities are shown in Fig. 3. 


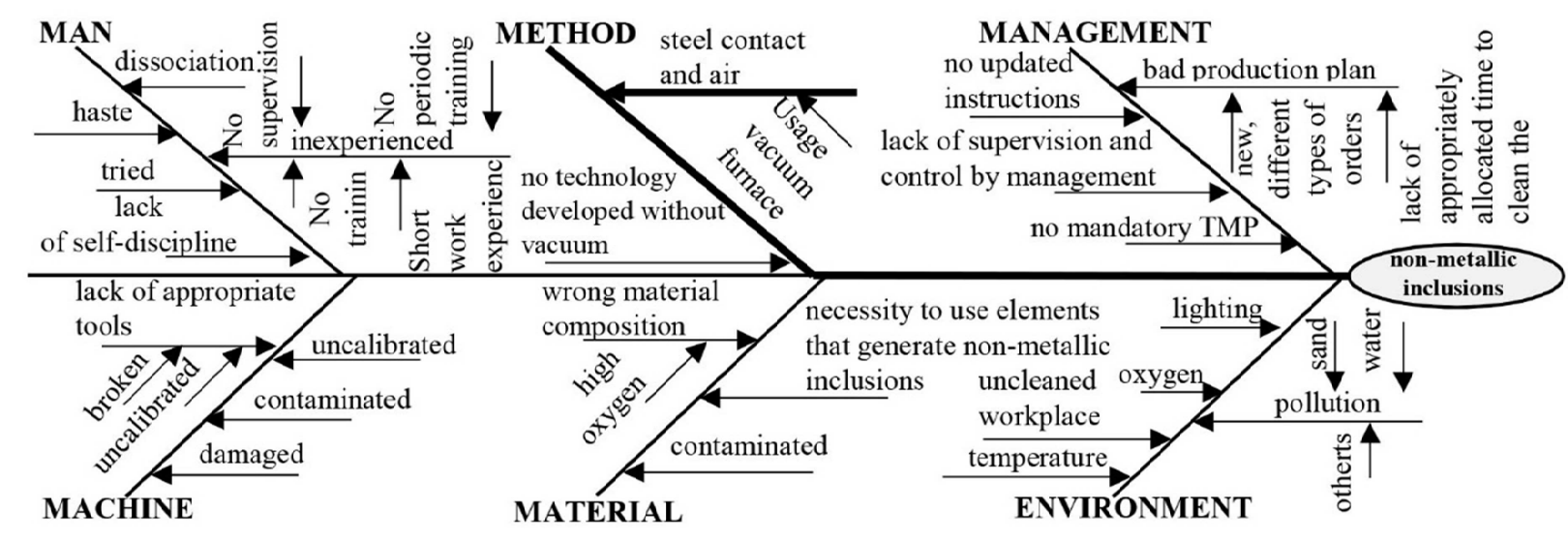

Fig. 3. The causes and effect diagram for the problem of non-metallic inclusions on bearing housing 
The team of experts then selected the main cause of non-metallic inclusions on bearing housing using multiple voting. Accordance to the panel of experts, the main cause was the contact between steel and air. Next, the team of experts identified the causes in the source of the problem. For this purpose, the 5Why method (i.e. Why-Why) was carried out in the context of the problem of non-metallic inclusions on bearing housing, and the main cause of this problem, i.e. contact between steel and air (Fig. 4).

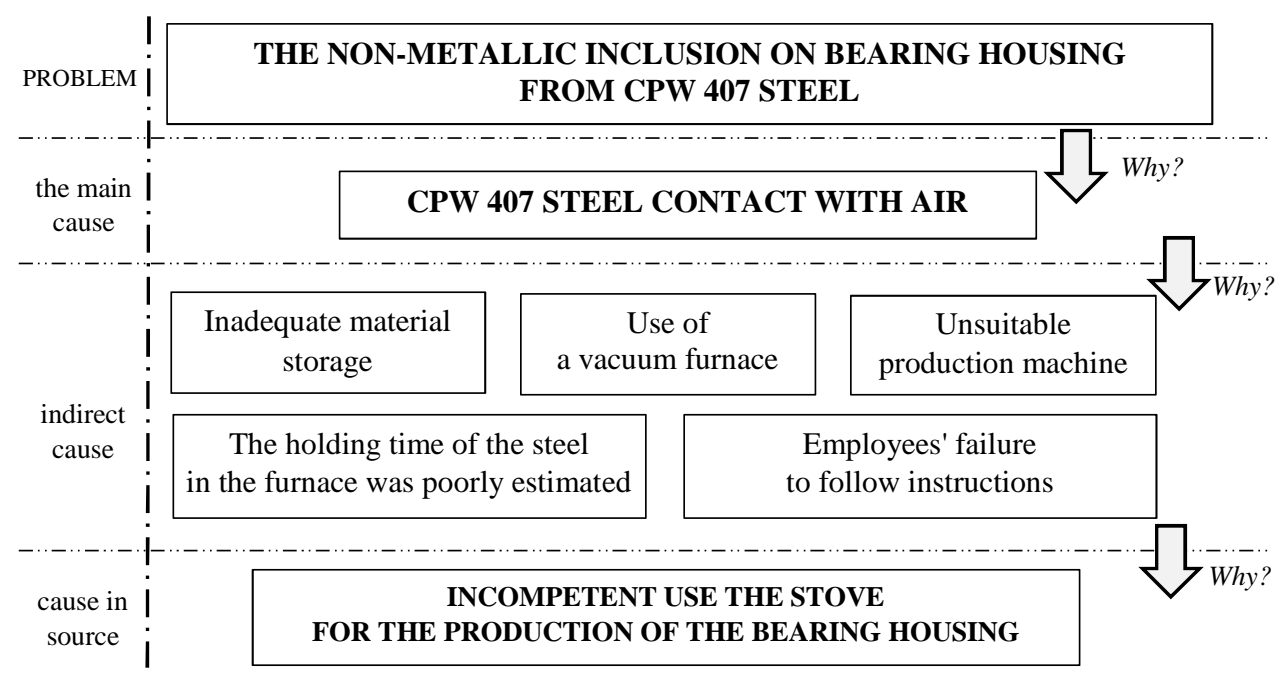

Fig. 4. The 5 Why method to identify the cause in source of non-metallic inclusions on bearing housing

It was concluded that the root cause of the problem was the incompetent use the stove for the production of the bearing housing.

In order to determine improvement actions, thanks to which it will be possible eliminate or reduce the problem, the whole procedure of the proposed method was repeated (from stage 2.2.). Therefore, by using brainstorming (among the panel of experts) improvement actions were generated. Then, all improvement actions were grouped into selected Ishikawa categories. This stage is visualized on the causes and effects diagram (Fig. 5).

Then, through multiple voting, the team of experts selected the improvement actions they felt should be implemented first. These actions include: introducing the obligation to use the instructions every time, introducing periodic training, making it mandatory for employees to participate in these, updating manuals, and introducing mandatory TMP (Total Productive Maintenance) of the machine. The aim of the TPM is to ensure the maximum efficiency of the machine. After the implementation of these actions it is possible to implement the next improvement actions, e.g. those indicated in the cause and effect diagram. 


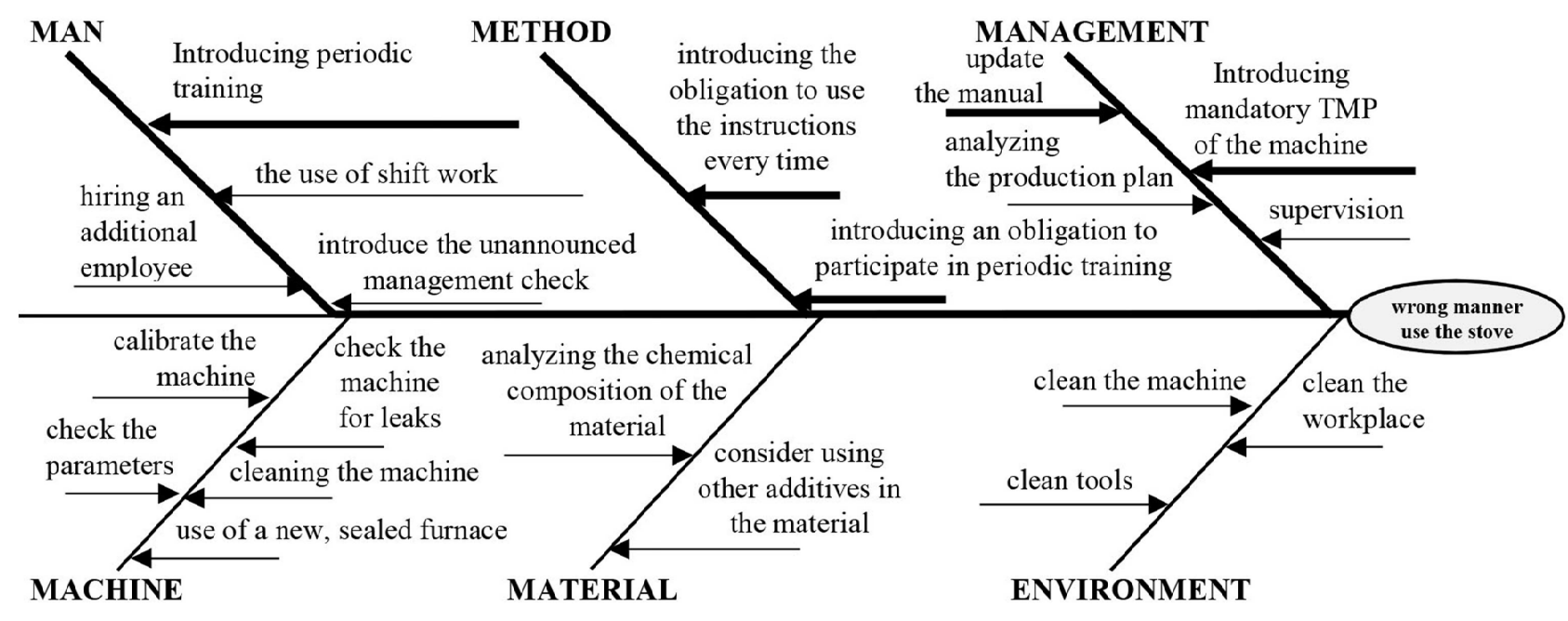

Fig. 5. The causes and effects diagram in the context of improvement actions of problem the non-metallic inclusions on bearing housing 


\section{CONCLUSIONS}

In the area of the constant development of enterprises and the need to meet customers' requirements, it is crucial to effectively solve the arising problems and prevent them from occurring in the future. In this context, it is effective to use the appropriately selected tools and methods. Therefore, the aim of the article is to propose the combination of the selected quality management instruments to identify the incompatibilities and causes of their occurrence, which is realized in a sequential and repetitive manner. Brainstorming (BM), causes and effects diagram, multiple voting, and the 5Why method were the combination. This method is based on five main stages, which can be used in a sequential and repetitive manner. The concept of the proposed instrument combination allows to generate the causes of the problem. This is done by brainstorming (BM). Then, according to some categories (thematic groups), e.g. Ishikawa rule $5 \mathrm{M}+\mathrm{E}$, all causes are grouped and visualized on the causes and effects diagram. In order to identify the main cause (i.e. the cause which contributed most to the problem), the team of experts uses multiple voting. The 5Why method is then used to look for the root cause of the problem. Then, it is necessary to repeat the process, but in the context of identifying improvement actions. The proposed combination of selected quality management techniques was shown to be effective in identifying the causes of problems and improvement actions. The effectiveness of the method is confirmed by the test which was done for the problem of non-metallic inclusions on bearing housing made of CPW 407 steel. This problem was relatively common in a Podkarpacie enterprise. These incompatibilities were identified in the enterprise by non-destructive testing (NDT), i.e. the magnetic-powder. Since this problem generated many material defects which can significantly influence the performance of the product, it was considered reasonable to analyze it. After applying the proposed method, it was concluded that the main cause of the non-metallic inclusions on bearing housing of CPW 407 steel is the incompetent use the stove for the production of this product. On the other hand, the improvement actions indicated that, as the first of the actions, is necessary to introduce the obligation to use the instructions every time, to introduce periodic training and the obligation of employees to participate in it, to update the instructions and to introduce mandatory TMP of the machine. It was concluded, that this method is effective, and the proposed combination of selected quality management techniques as part of a single method can be integrated with the non-destructive testing (NDT). Also, this method can be used to solve different incompatibilities in products from production and service enterprises.

\section{REFERENCES}

Blocker, C., Flint, D., Myers, M., Slater, S. (2011). Proactive customer orientation and its role for creating customer value in global markets. "J. of the Acad. Mark. Sci." 39. DOI: 10.1007/s11747-010-0202-9.

Cegliński, P. (2015). Najpopularniejsze instrumenty zarzadzania. Przeglad badań empirycznych. „Acta Universitatis Nicolai Copernici” 1. DOI: 10.12775/AUNC_ZARZ.2015.002.

Cioccia, M. (2017). The Fishbone diagram to identify, systematize and analyze the sources of general purpose technologies. "Journal of Social and Administrative Sciences" 4(4).

Dziuba, S., Jarossova, M., Gołębiecka, N. (2014). Applying the 5 Why method to verification of non-compliance causes established after application of the Ishikawa diagram in the process of improving the production of drive half-shafts. "Production Engineering Archives" 2(1). 
Ershadi, M., Kazemi, R. (2018). Root cause analysis in quality problem solving of research information systems: a case study. "Int. J. Productivity and Quality Management" 24(2).

Gołaś, H., Mazur, A., Mrugalska, B. (2016). Application of risk analysis and quality control methods for improvement of lead molding process. "Metalurgija" 55(4).

Hamrol, A. (2008). Zarządzanie jakościa z przyktadami. Warszawa: PWN.

Ilie, G., Ciocoiu, C. N. (2010). Application of fishbone diagram to determine the risk of an event with multiple causes. "Management Research and Practice" 2(1).

Ishii, K., Lee, B. (1996). Reverse Fishbone Diagram: A tool in aid of design for product retirement. "ASME DFM" 1-19.

Lawlor, K. B., Hornyak, M., J. (2012). Smart Goals: How The Application Of Smart Goals Can Contribute To Achievement Of Student Learning Outcomes. "Developments in Business Simulation and Experiential Learning” 39.

Li, W., Pomegbe, W., Dogbe, C. (2018). Employees' customer orientation and customer satisfaction in the public utility sector. The mediating role of service quality. "African Journal of Economic and Management Studies". DOI: 10.1108/AJEMS-10-2018-0314.

Lis, T. (1995). Odsiarczanie stali wapniem i magnezem z udziatem tlenkowej fazy dyspersyjnej. „Hutnictwo. Zeszyty Naukowe Politechniki Śląskiej”, z. 49.

Luo, T., Wu, C., Duan, L. (2018). Fishbone diagram and risk matrix analysis method and its application in safety assessment of natural gas spherical tank. "Journal of Cleaner Production” 174. DOI: https://doi.org/10.1016/j.jclepro.2017.10.334.

Nilsson, L., Johnson, M., Gustafsson, A. (2001). The impact of quality practices on customer satisfaction and business results: product versus service organizations. "Journal of Quality Management" 6.

Pacana, A., Siwiec, D. Bednarova, L. (2019). Analysis of the incompatibility of the product with fluorescent method. "Matalurgija" 58(3-4).

Pacana, A., Siwiec, D., Bednárová, L. (2020). Method of Choice: A Fluorescent Penetrant Taking into Account Sustainability Criteria. "Sustainability", 12. DOI: 10.3390/ su12145854.

Pacana, A., Siwiec, D., Bednarova, L., Hajduova, Z. (2019). Wybrane metody zarzadzania jakościa stosowane do oceny druku etykiet. „Przemyst Chemiczny” 98(1). DOI: 10.15199/ 62.2019.1.17.

Putman, V., Paulus, P. (2008). Brainstorming, Brainstorming. Rules and Decision Making. "Journal of Creative Behavior".

Rossiter, J., Lilien, G. (1994). New “Brainstorming” Principles. "Australian Journal of Management" 19(1).

Siwiec, D., Bednarova, L., Pacana, A. (2020). Metoda doboru penetrantów dla przemystowych badań nieniszczacych. „Przemyst Chemiczny” 99(5). DOI: 10.15199/62.2020.5.18.

Ulewicz, R. (2014). Practical application of quality tools in the cast iron foundry. "Manufacturing Technology" 14(1).

Wolniak, R. (2019). Downtime in the Automotive Industry Production Process - Cause Analysis. “Quality Innovation Prosperity” 23(2). DOI: 10.12776/QIP.V23I2.1259.

DOI: $10.7862 /$ rz.2021.mmr.05

The text was submitted to the editorial office: January 2021.

The text was accepted for publication: March 2021. 